\title{
Who is Benefitting? International Professional Development for Teachers
}

\author{
William D. Edgington \\ Sam Houston State University (SHSU), Texas, United States \\ Galina Kitaygorodskaya \\ Ministry of Education, Science, and Youth Policy, Komi Republic, Russia \\ Natalia Novokova \\ Syktyvkar State University, Komi Republic, Russia
}

\begin{abstract}
If the world is indeed becoming "smaller", as the platitude suggests, the opportunities to reach out to colleagues in professional discourse should be employed. How does it happen that colleagues are able to exchange ideas and assess the practice of others? It is one thing for policy-makers to discuss pedagogy and philosophy, but how will that translate into practice? If global dialogs are meant to be influential, the importance of those directly affected (that is, teachers) cannot be understated. This paper describes the collaboration between an American University and a regional Ministry of Education in the Russian Federation in an attempt to bridge the cultural gap between two nations and promote effective teaching in public schools. The collaboration was considered to be a pilot project in order to evaluate feasibility, time, cost, adverse effects, and design. The findings indicate a positive experience for both the participants and presenters. That is, all indications point towards the participants believing the professional development made them more effective in their classroom and that a certain amount of cultural understanding had transpired. The stated needs by participants for future professional development and the need to help build relationships through more informal interaction will certainly be taken into consideration when planning ensuing collaborations.
\end{abstract}

Keywords: international education, professional development, cross-national studies, diversity and education, knowledge exchange

If the world is indeed becoming "smaller", as the platitude suggests, the opportunities to reach out to colleagues in professional discourse should be employed. The resulting shared visions and conversations should, in turn, be put into practice and examined for effectiveness and practicality. This is no less appropriate for education and teacher preparation as it is for other fields of study and endeavor. Comparing purpose, pedagogical assumption, implementation, and assessment ideology in connection with results should only serve to reaffirm or debilitate national, state, and local educational practices. Von Kopp (2010) suggested that

William D. Edgington, Dr., professor, School of Teaching and Learning, Sam Houston State University (SHSU), Texas, United States.

Galina Kitaygorodskaya, Ph.D., rector, Ministry of Education, Science, and Youth Policy, Komi Republic, Russia.

Natalia Novokova, Ph.D., professor, Department of General Technical Disciplines and Methods of Teaching, Syktyvkar State University, Komi Republic, Russia. 
comparative education is by nature "border crossing" and, when viewed in that context, it remains favorable for snapshots of theory, research, and practice.

There has been a great deal of imploring for the need for comparative education in a globalized society. Schleicher (2011) emphasized that comparative education has the capacity to enable nations to set measurable goals by considering the structure and accomplishments of other nations, and to ascertain the process and practicality of their own system. Konig and Blomeke (2012) expressed the value of comparative education in determining effectiveness in teacher preparation programs. Though globalization has the potential to promote convergence and standardization in education across geographic and political boundaries, Von Kopp (2010) argued that "a comparative education which is adopted and continuously adapted to the contradictory changes is needed more than ever" (p. 11).

Ultimately, engaging in comparative education dialog with colleagues in global contemporary education systems serves two purposes. First, it enables one assembly to reflect on the practices and effectiveness of their own system and make decisions, both in policy-making and in pedagogy, to enhance their educational praxis. Second, participation in global colloquy provides opportunity to transcend ethnocentrism and assist colleagues in their assessment of their own systems. While these two purposes are certainly important and potentially impactful, how does it happen that colleagues are able to exchange ideas and assess the practice of others? It is one thing for policy-makers to discuss pedagogy and philosophy, but how will that translate into practice? If global dialogs are meant to be influential, the importance of those directly affected (that is, teachers) cannot be understated. This is how effectiveness and practicality are examined in education: Is the action pedagogically sound and can it be put into practice? As effectiveness and practicality are the main observable outcomes of professional development, it is reasonable to look to professional development as a means of global dialog.

\section{International Professional Development}

There have been attempts at distinguishing the commonalities and differences between teachers on an international level. Goodall (2014) concluded that cultural differences are an important consideration and potential hindrance when conversations take place among educators from various nations; expressly among those with individualist and collectivist histories. Yet, it can be argued that comparative perspectives could "help to inject a more critical, reflective and context sensitive dimension into continuing professional development for teachers" (Crossley \& Watson, 2009, p. 644). Lunenberg, Murray, Smith, and Vanderlinde (2017) emphasized that working in transnational contexts can be influential in learning without sacrificing individual or national perspectives. While there have been reports that examined the effects of participating in transnational education consortiums and forms (Lunenberg et al., 2017; Thakrar, Zinn, \& Wolfenden, 2009), there has been few attempts to determine who benefits from international professional development for teachers and in what ways. While Corey, Lemon, Gilbert, and Ninomiya (2016) did look at the benefits of a particular method of Japanese professional development on American teachers, the focus appeared to be on the method rather than the content or impact. So, the question remains: Are we using global dialog in education for the practical benefit of teachers, and ultimately, students?

This paper describes the collaboration between an American University and a regional Ministry of Education in the Russian Federation in an attempt to bridge the cultural gap between two nations and promote effective teaching in public schools. The collaboration was considered to be a pilot project in order to evaluate feasibility, time, cost, adverse effects, and design. 


\section{The Collaboration}

Sam Houston State University (SHSU) in Huntsville, Texas and the Ministry of Education, Science, and Youth Policy of the Komi Republic in the Russian Federation partnered in June of 2018 to provide professional development for teachers in the Komi Republic. SHSU faculty had previously participated in professional development for teachers in the Republic through Skype in the fall of 2017. This time, however, faculty traveled to the Republic with students in the SHSU Comparative and Global Education graduate program to help provide professional development during a two-day conference. The three students, each a certified teacher in public schools in Texas, designed and provided for Russian teachers sessions that corresponded with their particular area of interest and experience. The SHSU faculty, along with members of the Ministry, provided sessions as well. Session topics included the use of information technologies in education, the implementation of professional learning communities, civic education, project-based learning, and the challenge of inter-cultural communication in education. Over the course of the conference, 31 sessions were offered for teachers and representatives from SHSU were involved in 16 of the sessions. A translator was at every session to provide assistance in both English and Russian. Presenters and participants were surveyed afterwards to help determine the extent of success in helping to make teachers more effective in the classroom and the degree to which cultural understanding had occurred.

It was important to attempt to ascertain the impact of the professional development on the participants both professionally and personally, and so the survey for participants included four questions that used a Likert-type scale to explore "personal insight" and four questions that used a Likert-type scale to explore "professional insight". Participants' "overall insight" was examined through six open-ended questions. The survey was constructed specifically for this endeavor (see Appendix A), and translated into Russian. There were over 50 participants, and 27 returned their surveys.

Similarly, the survey for SHSU presenters was intended to probe their perceptions of the professional development in terms of professional and personal context, but also to explore their feelings about traveling abroad, and how it related to their graduate program. Their survey included eight questions that used a Likert-type scale to explore "personal insight" and four questions that used a Likert-type scale to explore "professional insight". Presenters' "overall insight" was examined through nine open-ended questions. The survey was constructed specifically for this project (see Appendix B), and completed by all three SHSU graduate student presenters.

\section{Results of Participants' Survey}

\section{Professional Insight}

Statement: The professional development sessions were relevant to my current job functions.

Six participants responded with a "strong yes" and 15 participants answered "yes". Five participants answered neither "yes" nor "no". One respondent did not answer the question. With each of the statements, the participants may have been confused with the translation.

Statement: The professional development sessions will help me to do my job better.

Five participants felt "strongly" that "yes", the sessions would help them perform their job better and 12 answered "yes". Eight answered with a neither "yes" nor "no" response and one responded with a "strong no"; the sessions would not help them do their job any better. One respondent did not answer the question. 


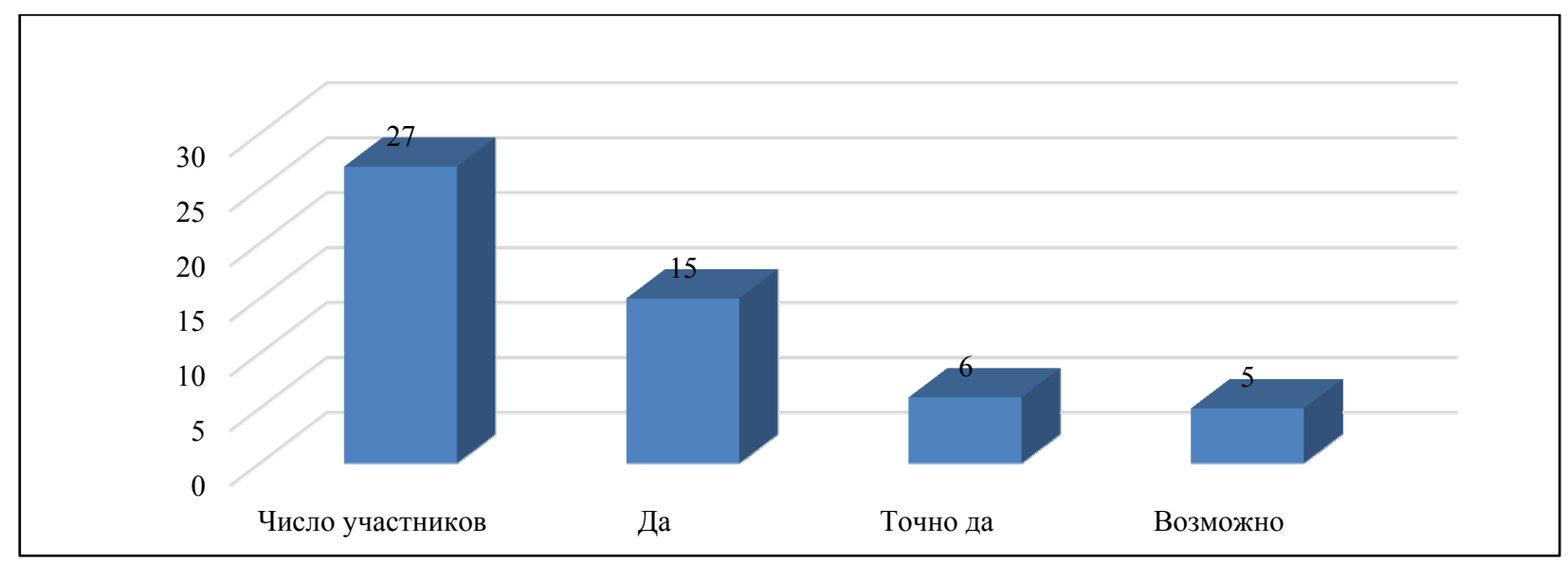

Figure 1. Relevant Sessions.

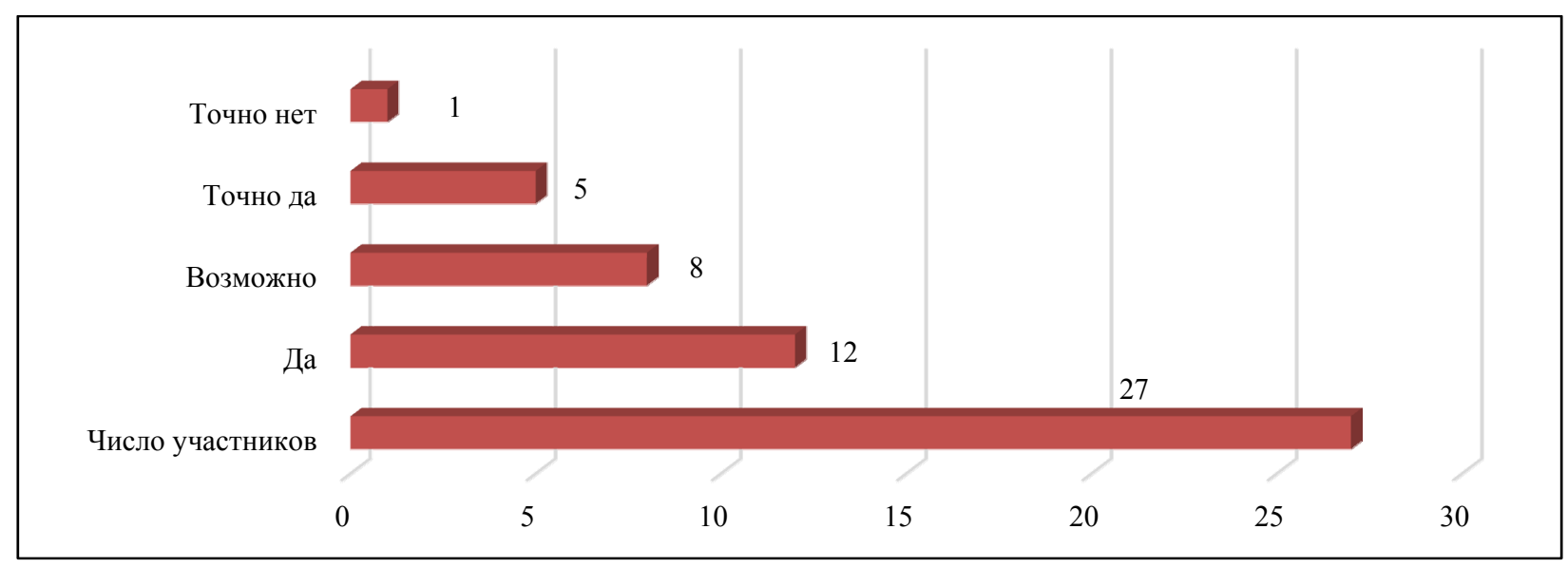

Figure 2. Helpful Sessions.

Statement: The professional development sessions will help me to better help students and/or work with my colleagues (The translated statement omitted "help students and/or").

Two participants answered with a "strong yes" while 12 answered "yes". Eleven answered neither "yes" nor "no" and one answered "no". One respondent did not answer the question.

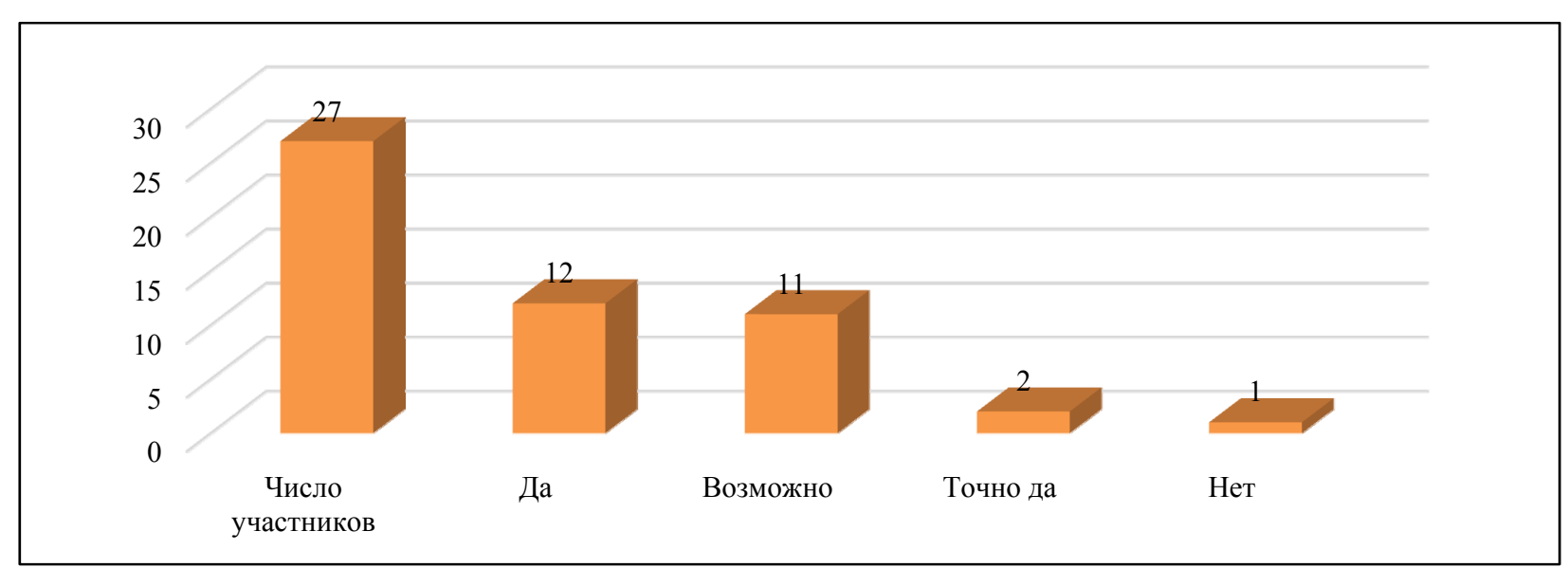

Figure 3. Help/Work with Students/Colleagues. 
Statement: I have gained a new perspective on other cultures in regards to education.

Four felt "strongly" that "yes", they did gain a new perspective and 14 answered "yes". Five responded with neither "yes" nor "no", two answered "no", and one answered "strongly no". Some participants may have felt the need to interact more with presenters in order to gain new perspectives. One respondent did not answer the question.

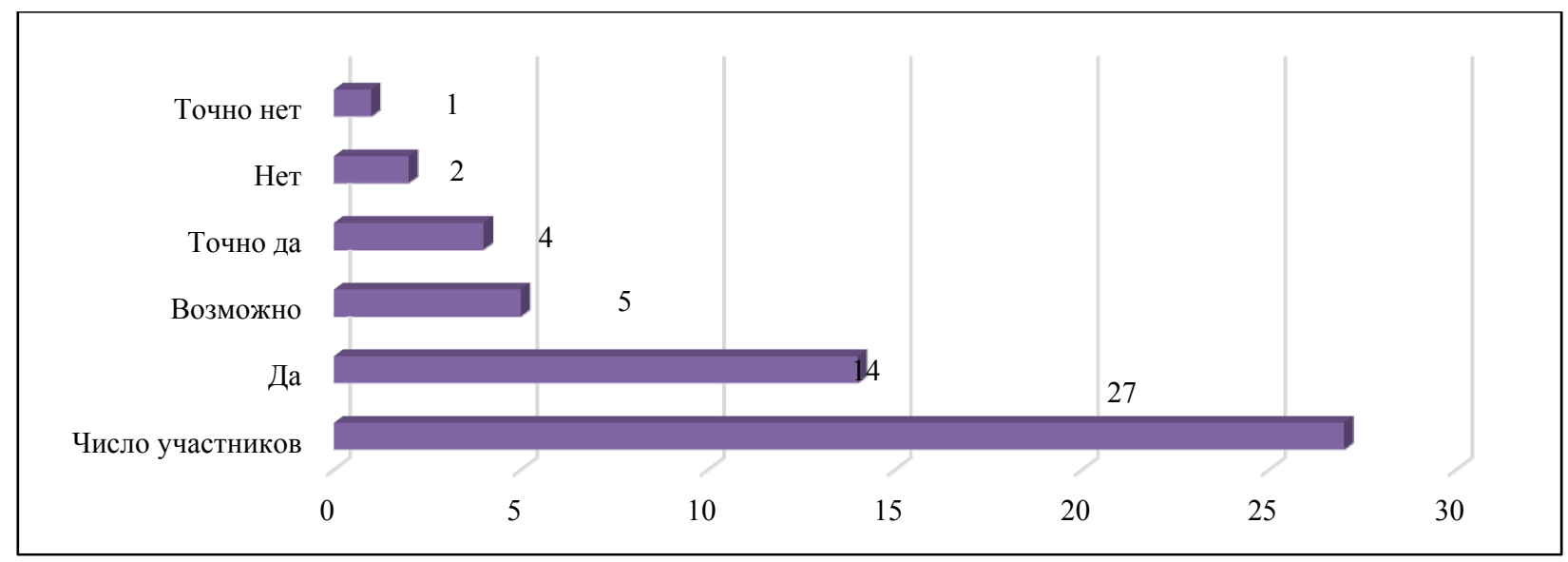

Figure 4. New Perspective on Other Cultures.

\section{Personal Insight}

Statement: I have built relationships with colleagues on an international level.

One participant answered with a "strong yes" and six answered "yes". Six answered with neither "yes" nor "no" and 13 felt they "did not" build relationships. One respondent "did not" answer the question. Again, limited interaction may have led to not building relationships.

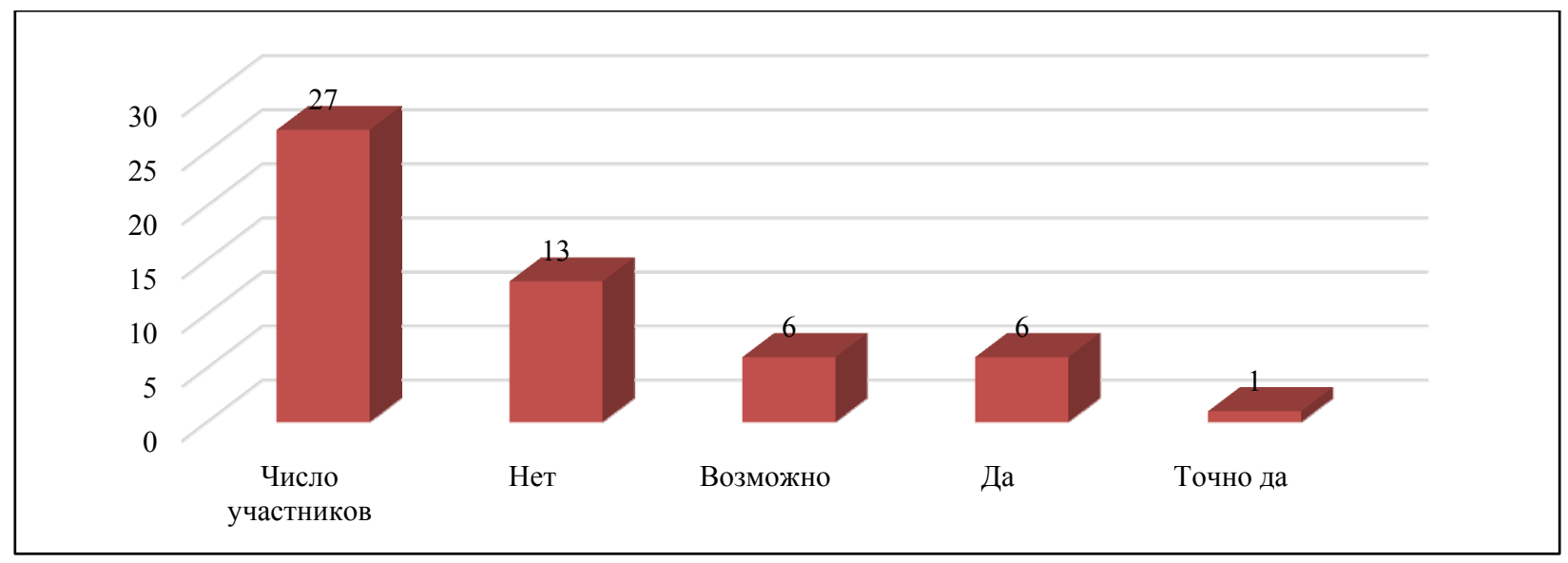

Figure 5. Built International Relationships.

Statement: I have gained understanding of the professional environment in another country.

Four participants answered with a "strong yes" and 15 answered "yes". Six answered with neither "yes" nor "no" and one answered with a "no". One respondent did not answer the question.

Statement: I have nurtured a global network for potential collaboration or career opportunities in the future. 


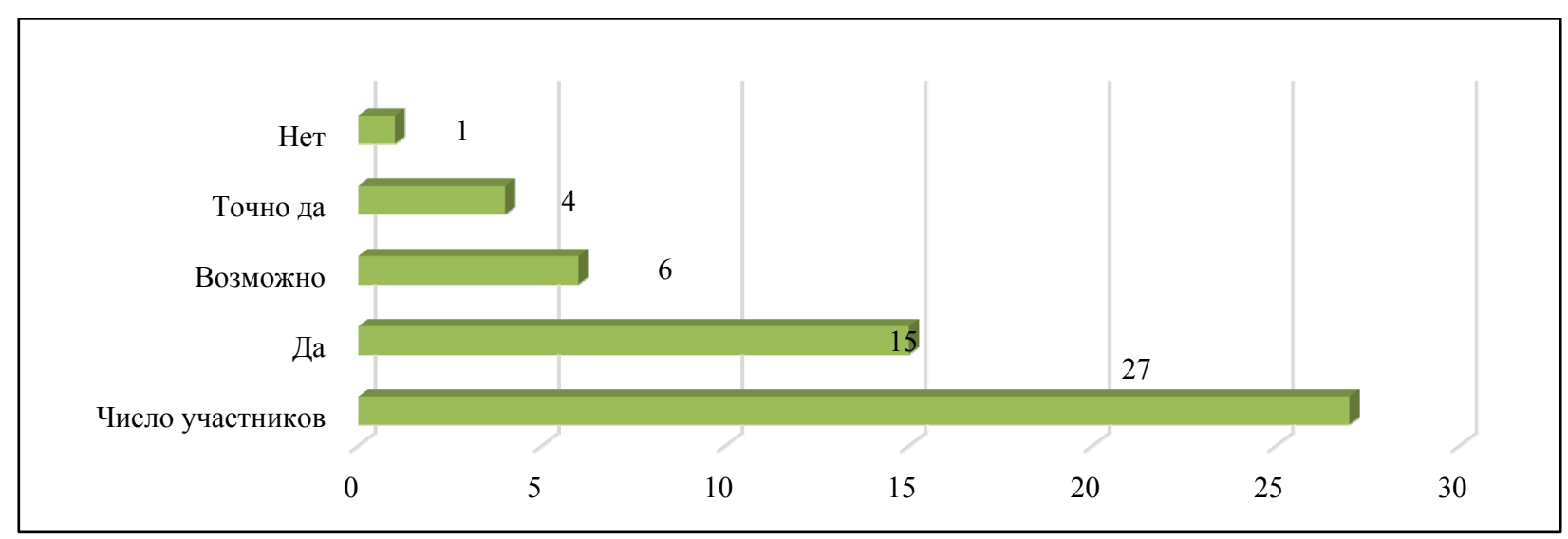

Figure 6. Understanding of Professional Development in Another Country.

One participant responded with a "strong yes" and five answered "yes". Seven responded that they neither "yes" nor "no" and 12 answered "no". One participant was not sure of the meaning of the statement and one participant did not answer the question.

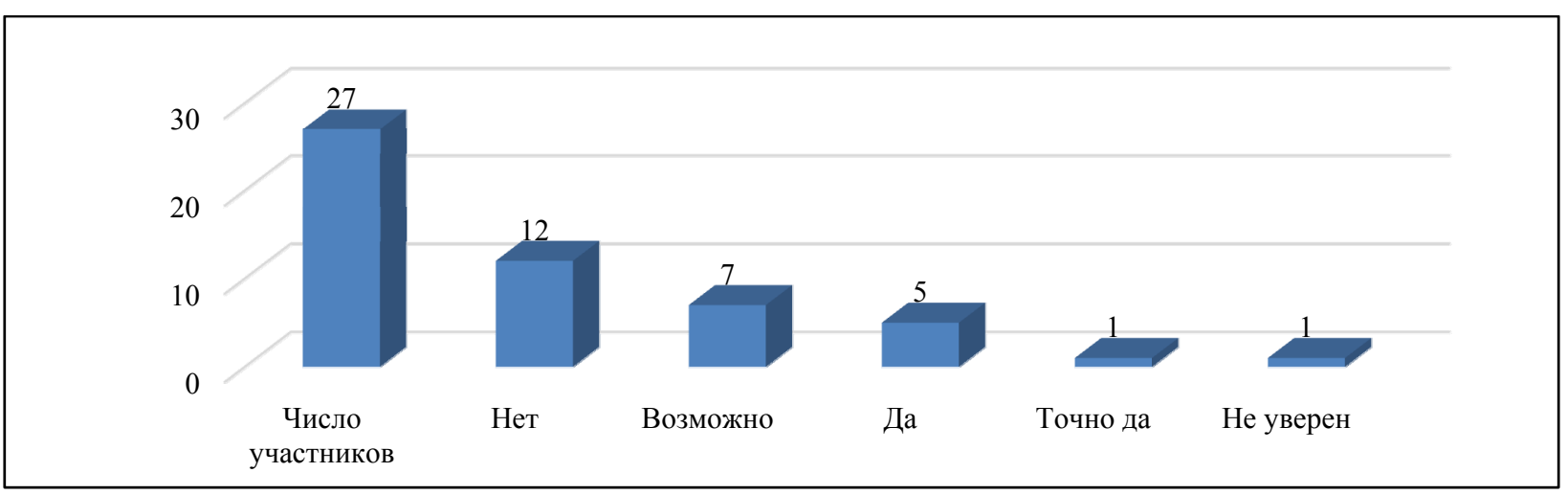

Figure 7. Global Network for Potential Collaboration.

Statement: My career plans have changed or expanded.

Eight participants responded with a "yes". Nine responded that they neither "yes" nor "no" and seven answered "no". One participant was not sure of the meaning of the statement and one participant did not answer the question.

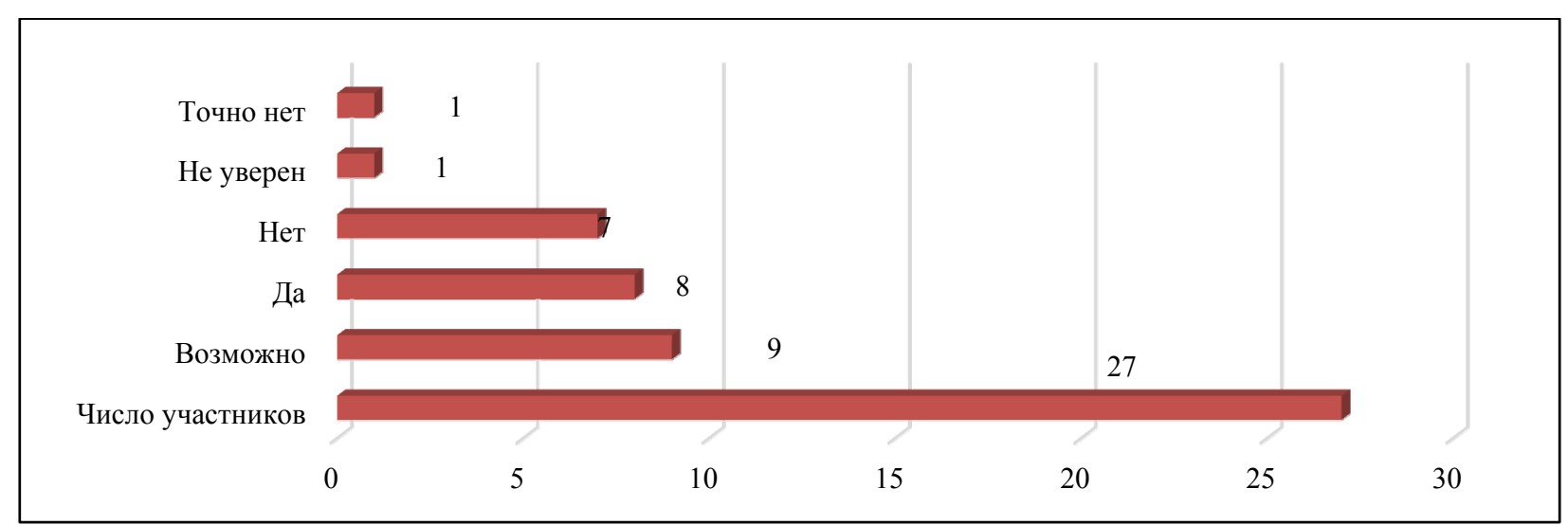

Figure 8. Changed or Expanded Career Plans. 


\section{Overall Insight}

Among the comments given for the most desirable aspects of the professional development were:

- Opening of new educational opportunities for children.

- Getting experience in communication and, as a result, improving mood.

- General intellectual development, expansion of the circle of communication and, as a result, formation of a new view on education in the world.

- The realization that work is being done in the right direction.

- Obtaining an understanding of the professional environment in another country through familiarization with interesting information, understanding of the activities of teachers abroad, which resulted in a desire to engage in new interesting work in a wider format, to take leading positions, and to increase pedagogical optimism.

- Opening access to advanced technologies, mastering modern competencies in the field of professional activity.

- The direct consequences of the discovery of this access were the great interest in the pedagogical experience of other countries, respect and great sympathy for the American colleagues in the process of communication. The emergence of self-confidence and the acquisition of knowledge about the similarity of problems in the education system of the United States and Russia. For this reason, the approaches presented by colleagues can be applied in our schools.

Among the comments given for least desirable aspects of the professional development were:

- The inability to work in different seminars (sessions), which are held simultaneously.

- The introduction of some innovations and innovations that are not adapted to the regional mentality and possibilities.

- Very difficult understanding of the presentation in English.

- Lack of conditions for the formation of professional competence.

Among the comments given for the primary benefits derived from the professional development were:

- Increase wages.

- Improvement of qualification, growth of professionalism.

- The emergence of opportunities to expand the educational framework for students.

- Competitiveness, performance associated with the experience of communicating with foreign teachers.

- The organization of conditions in the learning process for the initiation of students' actions in obtaining knowledge was combined with the motivation of self-development, the desire to improve, to acquire all the new knowledge and skills, to enrich the activity.

- The high level of professionalism of the teacher was undoubtedly achieved by improving the quality of education again through communication with colleagues and a review of previous experience.

Note: Some participants took the question to mean benefits from professional development in general, rather than this specific conference and others were not sure of the meaning.

Some suggestions for possible topics in international professional development in the future were:

- Information technology in the educational process.

- Improving the quality of education.

- Psychological aspects of inclusive education, interactive learning, working with gifted students.

- The use and creation of didactic games using Internet resources, the use of ready-made games with the ability to create your own tasks. 
- Development of the digital educational environment of the region and the revitalization of professional network communities.

- Ability to test students' knowledge by mobile phone.

- Work with students who are lagging behind and behind.

- Competences of teachers from other countries.

Among the responses for how this experience would help them achieve future career goals were:

- Organize similar events as part of their responsibilities.

- Participation in seminars is the development of abilities for successful communication, teamwork, improvement of professional knowledge, skills, and abilities.

- My career goal is to organize the most effective learning process. Skillful use of didactic games will provide an opportunity to achieve the goal.

- Will give the opportunity to participate in international projects.

- I think that will positively reflect in my work.

- The acquired experience helped me to orient myself, to break my goal into several smaller stages, in terms of achieving the goal for motivating students to study the subject, and, consequently, to improve the quality of my work, improve understanding between me and the students of my classes.

- Any experience gained in the process of learning or communicating with colleagues is valuable and useful for achieving career goals in the future.

- Apply the knowledge gained in your practice.

\section{Results of Presenters' Survey}

\section{Professional Insight}

Because there were only three presenters to survey, charting their responses will not be necessary, and though means have been calculated for the Likert-type questions, we are choosing to report in a narrative. The vast majority of the statements in this section were answered with a "strong yes" or "yes". The only exception was that one presenter chose neither "yes" nor "no" to the statement of career plans changing or expanding. The others answered with a "strong yes" and "yes".

\section{Personal Insight}

The vast majority of the statements in this section were answered with a "strong yes" or "yes". One presenter selected neither "yes" nor "no" to the statement of whether they had gained a new perspective of their own country, while the others gave a "strong yes".

\section{Overall Insight}

Note: Many of the open-ended questions for the presenters were geared to provide information for their graduate program, and those statements and responses will not be examined here, as they do not pertain to the direct experience of this project.

Among the comments given for the most desirable aspects of the professional development were:

- Meeting educators at different levels (teachers, professors, researchers, etc.).

- Experience sharing professional development.

- Collaborating with professionals cross culturally.

- Experiencing a new culture. 
The only listing for the least desirable aspect of the professional development was jet-lag!

Among the primary benefits given were:

- New understanding of professional interests in another country.

- Professional connections and potential research collaborations or professional development.

- Cross cultural learning.

- Professional understanding.

Responses to the question of how the experience will help them to achieve future goals included:

- It has helped me to learn about the ground level education concerns internationally.

- It has helped me to gain experience presenting.

- It has helped me gain experience coming up with solutions to other teachers' concerns.

- I enjoyed meeting others at the university level who might want to collaborate on research.

\section{Findings}

\section{Participants}

Concerning professional growth, the majority of participants felt that the sessions provided were relevant to their positions and were practical, and would help them do their jobs better. Most felt that the professional development they experienced would help them better work with colleagues; presumably with professional discussions and suggestions. As noted, the translated statement omitted "help students and/or", so although most participants responded that the sessions were relevant and would help them work with colleagues, we do not know if they believed the sessions would enable them to better help students. The majority believed they gained a new perspective on other cultures in regards to education and, as noted, because there was little interaction between presenters and participants between sessions, some may have felt limited opportunities to interact with the other cultures. Undoubtedly, some may have felt a gained perspective simply from learning about American educational philosophy and pedagogy.

In regards to personal growth, only seven believed they had built relationships with colleagues on an international level. Again, the limited interaction may have contributed to most participants not feeling as if relationships had been established. Yet, the majority believed they had gained understanding of the professional environment in another country. This was accomplished through content and skills addressed in the sessions rather than from informal interaction with the presenters. The lack of interaction is evident in that only six participants feel as if they have nurtured a global network for potential collaboration or career opportunities in the future; it is difficult to collaborate in education endeavors with those with whom a connection is not felt and that connection only comes with familiarity. While the sessions were relevant and helpful, only eight believed their career plans have changed or expanded as a result of the professional development. It is interesting to note that although one participant consistently did not answer the Likert-type scale questions, there was full participation for the open-ended questions. It could be the format of the Likert-type questions was confusing.

The answers to the open-ended questions regarding overall insight were encouraging. They seemed to appreciate the focus of the presenters to be one of sharing among equals. They also appreciated learning that the problems in education are not necessarily unique to one country but are shared; that internationally, teachers can relate to one another. In addition, one participant was pleased to learn that "work is being done in the right direction" in terms of Russian advancements in education. Some concerns about the conference were similar to concerns for seemingly all professional development: That because more than one session was occurring at the 
same time, participants had to choose between two in which they were potentially interested; that resources and strategies mentioned during a session may not be available in all areas of the Republic; and that at times the presentations in English, even though they were translated into Russian, may have been hard to understand. It should be noted that the translators provided were not versed in education and, as often is the case with translation, unfamiliarity with the context may hinder accurate transference. As was noted, some participants misunderstood the question of the benefits of this particular professional development to mean the benefits of professional development in general, and their answers were typical of teachers all over the globe: from helping to improve the quality of their teaching and professionalism to an increase in pay (either from simply attending the professional development or due to student success based on the professional development).

Suggestions for future topics in professional development indicate the desire for suggestions and specific training in the use of technology as an instructional tool in the classroom. Other suggestions included strategies in working with specific needs students, and assessment strategies. When asked if this experience would help them achieve future career goals, it was interesting to note that their career goals focused on being better teachers and educators and to improve the quality of their relationships with students. While not specifically addressing future career goals, one participant stressed the importance of professional collaboration: "Any experience gained in the process of learning or communicating with colleagues is valuable and useful for achieving career goals in the future."

\section{Presenters}

As far as professional insight, it was interesting that while one presenter did not see their career plans changing or expanding as a result of their experience, the others did. Both have indicated they want to get further involved with comparative education and continue to work internationally in education someday. Each felt they had built relationships with colleagues on an international level. It was interesting that each had a few informal conversations with participants and categorized those as building relationships, while less than a third of the participants felt that way. Similar to the participants, however, the presenters each felt that through the conference they had gained an understanding of the professional environment in another country.

In regards to personal insight, it was interesting to see that one presenter felt no new perspective of their country was gained, while the others felt strongly that the experience had done just that. That is understandable as often nationalism is heightened when away from the home country, or when asked to speak of the home country. In addition, seeing the home country through the lens of another person can lead to introspection.

The answers to the open-ended questions regarding overall insight indicate a positive experience for the presenters. The opportunity to collaborate cross-culturally as a professional was very much appreciated. From a personal standpoint, experiencing a new culture was very valuable to them. Cultural excursions were planned for the presenters and they experienced not only aspects of the Russian culture but of the Komi Republic, as well. Perhaps this helps explain why they felt more of a kinship with the teachers than many of the teachers felt with them; they were immersed to a greater degree with the others' culture. An interesting benefit of presenting at the conference and consideration for their future goals was the opportunities for further collaboration and research partnerships; only a small portion of participants had similar aspirations. This may be explained by the respective roles as presenters and participants, in that one gives and one receives. Also, the teachers indicated that they were involved in the professional development in order to assess and improve their teaching. The presenters, although teachers themselves, were also graduate students steeped in research details. 


\section{Conclusions}

In order to find additional promising directions, it is important to look at the answers of participants and presenters to formulate the following inferences based on this project:

- The ability to listen to another point of view can lead to discussion which enlightens both pedagogically and philosophically.

- General intellectual development is possible; that is, expansion of the circle of communication and as a result, the formation of a new look at education in the world.

- The introduction of some innovations and innovations that are not adapted to the regional mentality and capabilities can be combined with familiarization with interesting information and understanding of the activities of teachers abroad. This results in a desire to engage in new interesting business in a broader format, to take leading positions, to achieve a sense of pedagogical optimism.

- Although language can be a barrier, an understanding of the professional environment in another country is possible through communication with foreign teachers. Interest in the use of specific methods of instruction of teachers with students has a positive impact on teaching.

- The lack of resources to provide professional development makes it necessary to consider advanced technologies as a way to engage in professional activity. These technologies also serve to organize the conditions in the learning process to solve complex problems in the professional activities of the teacher, advance critical thinking in a teacher's professional activities, and contribute to the cognitive flexibility of the teacher.

- Sincere interest in the pedagogical experience of other countries can sometimes manifest itself in the pursuit of instructional improvement, the acquisition of new knowledge and skills and enrichment of activities. International professional development can result in more options for resolving various pedagogical situations and resolving conflicts. Thus, the teacher's professionalism increases; a necessary condition for improving the quality and improvement of both the pedagogical process and the education system as a whole.

- Something as simple as knowing that the problems and concerns a teacher faces are not unique to them and that teachers globally experience similar conditions can lead to empathy and trust, and professional understanding.

- Respect and great sympathy for international colleagues undoubtedly leads to an increase in the quality of education. The experience gained in the process of learning or communicating with colleagues is very valuable and can be useful for solving professional problems in the future.

\section{Considerations for the Future}

This project was designed with a post-conference survey specifically for participants and a survey specifically for the presenters from SHSU. In this way, it was hoped to gage perceptions as to attitude towards the practice of international professional development and potential effectiveness of information/skills presented at the conference. In the future, we would suggest using not only a post-conference survey, but also a follow-up survey of participants to determine if information/skills gathered during the conference were used in instructional practice or pedagogical foundations. In this way, effectiveness and practicality may be examined further. Also, because some answers indicated a lack of connection between the participants and presenters, it is recommended to build in time between sessions for informal interaction and discourse. 
Another consideration for the future involves the location of the professional development. At the time of the conference, the Russian Federation was under Level 3 Travel Advisory status as determined by the United States Department of State; that is, "Reconsider Travel". This status made the SHSU administration reluctant to allow the students to represent the university or to fund part of their trip. The location of international professional development is a very real consideration for those reasons.

So, can international professional development for teachers serve as global dialog? This pilot project, while small and admittedly emerging, indicates that it is a definite possibility. That is, all indications point towards the participants believing the professional development made them more effective in their classroom and that a certain amount of cultural understanding had transpired. The stated needs by participants for future professional development and the need to help build relationships through more informal interaction will certainly be taken into consideration when planning ensuing collaborations.

\section{References}

Corey, D. L., Lemon, T., Gilbert, E., \& Ninomiya, H. (2016). Japanese professional development. Mathematics Teaching in the Middle School, 21(9), 544-551.

Crossley, M., \& Watson, K. (2009). Comparative and international education: Policy transfer, context sensitivity and professional development. Oxford Review of Education, 35(5), 633-649.

Goodall, H. (2014). Middle East meets West: Negotiating cultural difference in international educational encounters. International Review of Education, 60(5), 603-617.

Konig, J., \& Blomeke, S. (2012). Future teachers' general pedagogical knowledge from a comparative perspective: Does school experience matter? ZDM: The International Journal on Mathematics Education, 44(3), 341-354.

Lunenberg, M., Murray, J., Smith, K., \& Vanderlinde, R. (2017). Collaborative teacher educator professional development in Europe: Different voices, one goal. Professional Development in Education, 43(4), 556-572.

Schleicher, A. (2011). Is the sky the limit to education improvement? Phi Delta Kappan, 93(2), 58-62.

Thakrar, J., Zinn, D., \& Wolfenden, F. (2009). Harnessing open educational resources to the challenges of teacher education in Sub-Saharan Africa. International Review of Research in Open and Distance Learning, 10(4), 1-16.

Von Kopp, B. (2010). Do we need comparative education in a globalized world? Orbis Scholae, 4(2), 7-20.

\section{Appendix A}

Ministry of Education, Science and Youth Policy of the Komi Republic

\section{Sam Houston State University}

Professional development survey

June, 2018

\section{Professional Insight}

Please rate your level of agreement or disagreement with each statement below.

\begin{tabular}{|c|c|c|c|c|c|c|}
\hline & NA & Strong yes & Yes & Neither & No & Strong no \\
\hline $\begin{array}{l}\text { The professional development sessions } \\
\text { were relevant to my current job functions }\end{array}$ & 0 & 1 & 2 & 3 & 4 & 5 \\
\hline $\begin{array}{l}\text { The professional development sessions } \\
\text { will help me to do my job better }\end{array}$ & 0 & 1 & 2 & 3 & 4 & 5 \\
\hline $\begin{array}{l}\text { The professional development sessions } \\
\text { will help me to better help students } \\
\text { and/or work with my colleagues }\end{array}$ & 0 & 1 & 2 & 3 & 4 & 5 \\
\hline $\begin{array}{l}\text { I have gained a new perspective on } \\
\text { other cultures in regards to education }\end{array}$ & 0 & 1 & 2 & 3 & 4 & 5 \\
\hline
\end{tabular}




\section{Personal Insight}

Please rate your level of agreement or disagreement with each statement below.

\begin{tabular}{|c|c|c|c|c|c|c|}
\hline & NA & Strong yes & Yes & Neither & No & Strong no \\
\hline $\begin{array}{l}\text { I have built relationships with colleagues } \\
\text { on an international level }\end{array}$ & 0 & 1 & 2 & 3 & 4 & 5 \\
\hline $\begin{array}{l}\text { I have gained understanding of the } \\
\text { professional environment in another country }\end{array}$ & 0 & 1 & 2 & 3 & 4 & 5 \\
\hline $\begin{array}{l}\text { I have nurtured a global network for } \\
\text { potential collaboration or career } \\
\text { opportunities in the future }\end{array}$ & 0 & 1 & 2 & 3 & 4 & 5 \\
\hline My career plans have changed or expanded & 0 & 1 & 2 & 3 & 4 & 5 \\
\hline
\end{tabular}

\section{Overall Insight}

Please answer each question in the space provided. Use additional space if necessary.

What were the most desirable aspects of the professional development?

What were the least desirable aspects of the professional development?

What are the primary benefits that you feel you derived from the professional development?

Are there any topics you would like to see addressed in the future?

How will this experience help you to achieve future career goals?

Are there any feelings or thoughts that you would like to express but have not had the opportunity?

\section{Appendix B}

\section{Sam Houston State University}

M.Ed.-Comparative and global education

Travel abroad experience

June, 2018

\section{Professional Insight}

Please rate your level of agreement or disagreement with each statement below.

\begin{tabular}{|c|c|c|c|c|c|c|}
\hline & NA & Strong yes & Yes & Neither & No & Strong no \\
\hline $\begin{array}{l}\text { I have built relationships with colleagues } \\
\text { on an international level }\end{array}$ & 0 & 1 & 2 & 3 & 4 & 5 \\
\hline $\begin{array}{l}\text { I have gained understanding of the } \\
\text { professional environment in another country }\end{array}$ & 0 & 1 & 2 & 3 & 4 & 5 \\
\hline $\begin{array}{l}\text { I have nurtured a global network for } \\
\text { potential collaboration or career } \\
\text { opportunities in the future }\end{array}$ & 0 & 1 & 2 & 3 & 4 & 5 \\
\hline $\begin{array}{l}\text { My career plans have changed or } \\
\text { expanded }\end{array}$ & 0 & 1 & 2 & 3 & 4 & 5 \\
\hline
\end{tabular}




\section{Personal Insight}

Please rate your level of agreement or disagreement with each statement below.

\begin{tabular}{|c|c|c|c|c|c|c|}
\hline & NA & Strong yes & Yes & Neither & No & Strong no \\
\hline \multicolumn{7}{|l|}{ As a result of this experience: } \\
\hline I have gained better insight into myself & 0 & 1 & 2 & 3 & 4 & 5 \\
\hline $\begin{array}{l}\text { I have a greater sense of independence } \\
\text { and self-confidence }\end{array}$ & 0 & 1 & 2 & 3 & 4 & 5 \\
\hline $\begin{array}{l}\text { My ability to adapt to new situations has } \\
\text { increased }\end{array}$ & 0 & 1 & 2 & 3 & 4 & 5 \\
\hline $\begin{array}{l}\text { I am more receptive to different ideas and } \\
\text { ways of seeing the world }\end{array}$ & 0 & 1 & 2 & 3 & 4 & 5 \\
\hline $\begin{array}{l}\text { I have gained a new perspective of my own } \\
\text { country }\end{array}$ & 0 & 1 & 2 & 3 & 4 & 5 \\
\hline $\begin{array}{l}\text { My interest in language learning has } \\
\text { increased }\end{array}$ & 0 & 1 & 2 & 3 & 4 & 5 \\
\hline $\begin{array}{l}\text { I have gained a new perspective on } \\
\text { other cultures }\end{array}$ & 0 & 1 & 2 & 3 & 4 & 5 \\
\hline $\begin{array}{l}\text { I am developing an ability to contextualize } \\
\text { the role of the United States in the world }\end{array}$ & 0 & 1 & 2 & 3 & 4 & 5 \\
\hline
\end{tabular}

\section{Overall Insight}

Please answer each question in the space provided. Use additional space if necessary.

What were the most desirable aspects of the experience?

What were the least desirable aspects of the experience?

What are the primary benefits that you feel you derived from the experience?

What sort of student would you recommend for future similar experiences?

If you were responsible for planning and implementing a similar experience, what changes would you make?

Before the experience, what did not you know that you wish you had known?

What advice would you give to others who might consider a similar experience in the future?

How will this experience help you to achieve future career goals?

Are there any feelings or thoughts that you would like to express but have not had the opportunity? 